\title{
Second Language Acquisition of English Unaccusative Verbs: A Theoretical Critique and Prospects for Future Studies
}

\author{
Junhua Mo \\ Soochow University, China
}

\begin{abstract}
Unaccusative verbs are a focus of second language acquisition research. Taking the second language acquisition of English unaccusative verbs as an example, this study first reviews the Unaccusative Hierarchy Hypothesis, the Unaccusative Trap Hypothesis and the Semantic Verb Class Hypothesis, which are exclusively concerned with the acquisition of unaccusative verbs. Then it examines the Entrenchment Hypothesis and the Interface Hypothesis, which address language acquisition in general, but shed light on the second language acquisition of English unaccusative verbs. This study maintains that these five hypothesis help to provide a panoramic view of second language acquisition of English unaccusative verbs. But it also points out that these hypotheses need to be further tested. It advises future studies to take a usage-based theoretical approach. It also calls for more attention to the possible between-verb variations, the possible influence of $\mathrm{LI}$ transfer and the online processing of English unaccusative verbs
\end{abstract}

Index Terms - second language acquisition, unaccusative verbs, theoretical critique, future prospects

\section{INTRODUCTION}

Verbs are an essential category of languages. Verbs that can be directly followed by nouns without the use of prepositions are called transitive verbs (e.g., destroy, touch), while those that cannot take noun objects are termed as intransitive verbs (e.g., happen, walk). This distinction, however, has proved to be inadequate in that the seemingly identical intransitive verbs are actually heterogeneous.

The Unaccusative Hypothesis (Burzio 1986; Perlmutter 1978) posits that intransitives, despite their surface similarity, can be further divided into unaccusatives and unergatives. The surface subject of an unaccusative verb (e.g., the subject window in the sentence The window broke) does not have a volition will and therefore cannot act as the instigator of the verb action. It is actually the recipient of the verb action and therefore the object at the underlying structure. Levin and Rappaport Hovav (1995) suggest that the distinction between unaccusatives and unergatives is determined by semantic factors and represented at the syntactic levels. At the semantic level, the only Noun Phrase (hence shortened as NP) of an unaccusative verb is the theme, while that of an unergative verb is the agent. At the syntactical level, the only NP of an unaccusative verb is the object at the deep structure, whereas that of an unergative verb is the subject at the deep structure.

The distinction between unaccusatives and unergatives has proved to be universal as it is found in English, Chinese, Korean, French, German, Italian, Spanish and many other languages. In English, some unaccusatives can be used as transitives without undergoing any morphological changes, while others cannot. They are called alternating unaccusatives and non-alternating unaccusatives respectively. A detailed classification of English intransitives is shown in Figure 1.

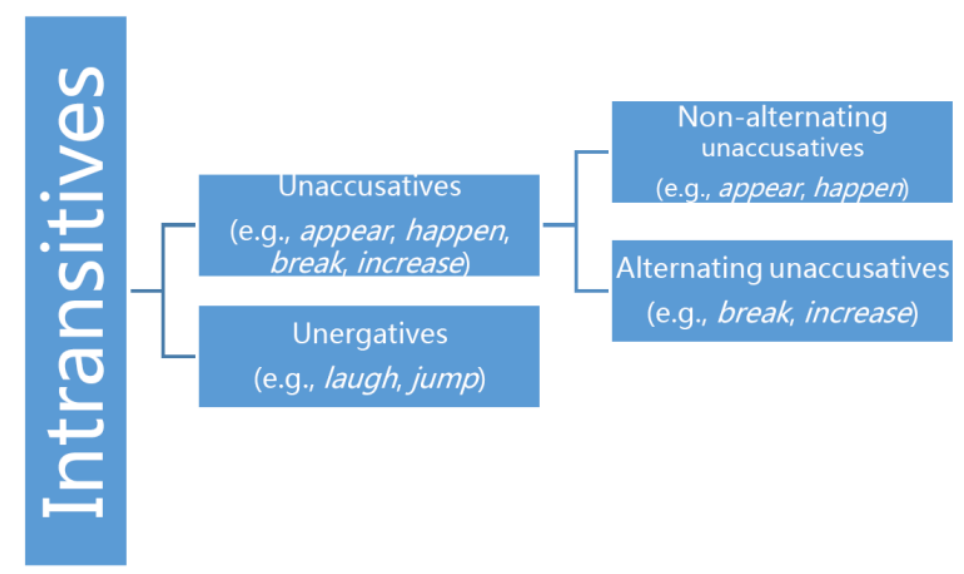

Figure 1. Classification of English intransitives 
The unique semantic and syntactic properties of English unaccusatives have posed a great difficulty to L2 learners, who tend to make overpassivization errors with unaccusatives, but not with unergatives. That is, L2 learners are apt to produce and accept ungrammatical and contextually inappropriate passive unaccusatives (e.g., ${ }^{* 1}$ A letter was arrived or *People's living standard has been improved).

The unique semantic and syntactic properties of English unaccusatives have also attracted the attention of L2 researchers, who have investigated various issues associated with L2 acquisition of English unaccusatives. These issues include the initial mental representation English unaccusatives, the developmental pattern of English unaccusatives and possible constraints on the L2 acquisition of English unaccusatives. Theories relevant to the acquisition of English unaccusatives, L1 and L2 alike, include the Unaccusative Hierarchy Hypothesis (Sorace, 1995), the Unaccusative Trap Hypothesis (Oshita, 1997, 2001), the Semantic Verb Class Hypothesis (Pinker, 1989), the Entrenchment Hypothesis (Braine and Brooks, 1995) and the Interface Hypothesis (Sorace and Filiaci, 2006). This study is going to make a theoretical critique of these hypotheses and suggest prospects of future studies of second language acquisition of English unaccusatives.

\section{A Theoretical Critique}

\section{A. The Unaccusative Hierarchy Hypothesis}

The Unaccusative Hierarchy Hypothesis, which is proposed Sorace (1995), posits that unaccusatives do not form a homogeneous group, but fall into semantically definable subgroups. It is based on the linguistic fact that unaccusatives do not appear to be the same in that some verbs display consistent unaccusative behaviors in various languages and in various contexts while other verbs do not. In her study of Italian unaccusatives, Sorace identifies three pairs of semantic determinants: dynamic/static, telic/atelic, and concrete/abstract. According to these criteria, monadic verbs denoting a change of location (e.g., come, go) are judged to be the core unaccusatives, whereas change of state verbs with a transitive counterpart (e.g., increase, melt) and manner of motion verbs with the addition of a directional phrase (e.g., run to the railway station) are considered to be the most peripheral unaccusatives. Change-of-condition verbs (e.g., appear, disappear) and existence-of-condition verbs like (e.g., exist, last) fall in between the core and peripheral unaccusatives. Thus, these verbs form a hierarchy, as shown in Table 1.1.

TABLE 1.

THE UNACCUSATIVE HIERARCHY BASED ON SORACE (1995)

\begin{tabular}{|c|c|c|}
\hline Unaccusative subgroups & Unaccusative verbs & Unaccusative hierarchy \\
\hline Change of location & go & \\
Change of condition & disappear & core \\
Continuation of a condition & last & exist \\
Existence of a condition & increase & $\downarrow$ \\
Change of condition with a transitive counterpart & peripheral \\
Manner of motion with a directional phrase & run to the railway station & \\
\hline
\end{tabular}

Sorace goes on to suggest that the acquisition of unaccusatives is dependent on their locations on the unaccusative hierarchy. Verbs that are placed higher on the hierarchy will be acquired earlier than those that stay at lower levels. As Table 1.1 shows, unaccusatives without transitive counterparts are placed higher on the hierarchy than those with transitive counterparts. Therefore, the former are predicted to be acquired before the latter.

\section{B. The Unaccusative Trap Hypothesis}

The Unaccusative Trap Hypothesis, which is initiated by Oshita (1997, 2001), suggests that L2 acquisition of unaccusatives undergoes a three-stage process, as shown Figure 2, 3 and 4.

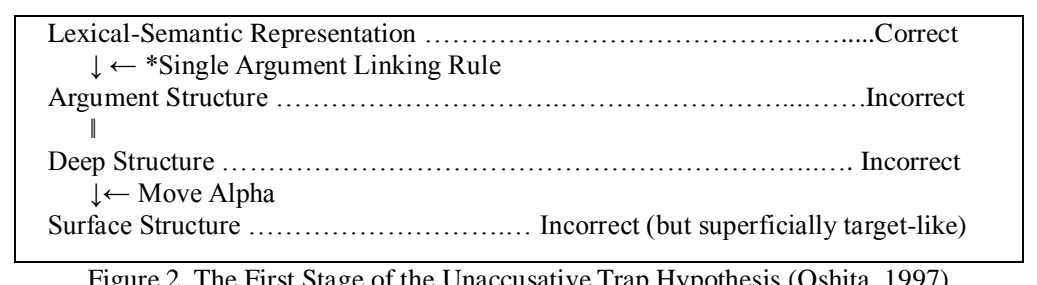

At the first stage, L2 learners do not make the distinction between unaccusatives and unergatives, possibly because of the prototypical Subject-Verb sentence pattern in the input. They are unable to detect the difference that the subject of the unaccusative verb has no volition and thus is not the agent, while that of the unergative verb is. At this stage, unaccusatives are lexically misunderstood as unergatives and as a result misrepresented as unergatives at the syntactic levels.

\footnotetext{
${ }^{1}$ Note: The symbol * stands for an error.
} 


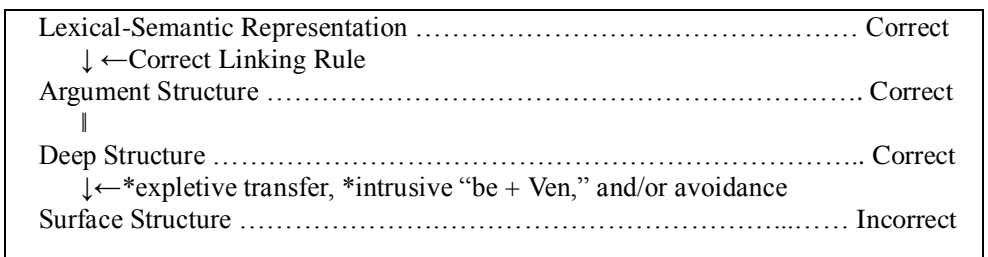

Figure 3. The Second Stage of the Unaccusative Trap Hypothesis (Oshita, 1997)

At the second stage, some learners perceive the subtle differences among the seemingly identical intransitive verbs and rebuild their mental grammars accordingly. Now they realize that the surface subjects do not always play the role of the external arguments or the actual agents. Some are in fact the internal arguments or the actual objects. This correct lexical analysis prompts them to establish the correct deep structure representation, at which the internal argument is placed in the object position. However, when they attempt to transfer the internal argument of the unaccusative verb from the deep structure object position to the surface structure subject position, they tend to explicitly mark this NP movement with the salient passive morpho-syntax be + Ven. As a result, the deep structure representation is correct, but the surface structure representation is wrong.

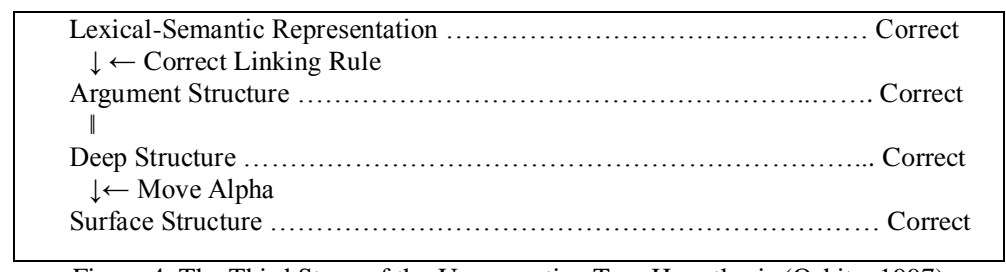

Figure 4. The Third Stage of the Unaccusative Trap Hypothesis (Oshita, 1997)

At the third stage, these learners make further progress and are competent in both correct lexical analysis and correct syntactic representations. Not only are they clear that the sole NP of the unaccusative verb is its internal argument, which should be projected onto the object position at the deep structure representation, but also prevent themselves from explicitly marking the NP movement with the salient passive morphosyntax be + Ven. In a nutshell, they are now target-like in the use of unaccusatives.

It's worth noting that the crux of the Unaccusative Trap Hypothesis is the state of the low-level learners' mental grammar about English intransitive verbs. These learners are assumed to misanalyze unaccusatives as unergatives. As a result, they don't make errors with unaccusatives and appear to be correct on the surface. In contrast, the intermediate learners are more likely to err with unaccusatives, making themselves look inferior to the low-level learners and plunging themselves to the bottom of the U-shaped developmental path. The Unaccusative Trap Hypothesis is important because it attempts to bring several unaccusative-related interlanguage phenomena together. Its importance also lies in the fact that it is the first hypothesis to address the developmental path of L2 acquisition of English unaccusative verbs.

\section{The Semantic Verb Class Hypothesis}

The Semantic Verb Class Hypothesis, which is put forward by Pinker (1989), postulates that the causative alternation is governed by a broad-range lexical rule. This rule licenses a verb which describes an event involving a thing to be included as an effect of an agent acting on that thing.

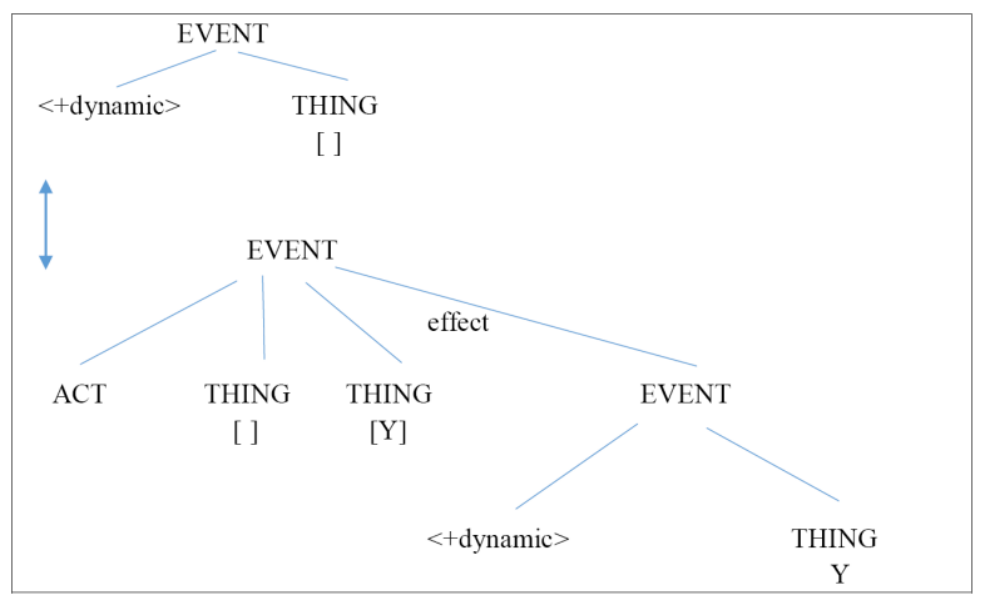

Figure 5. The Diagrammatical Representation of the Broad-range Rule for the Causative Alternation (Pinker, 1989)

The top part of Figure 5 represents a non-causative event (e.g., the window breaking), while the node $\langle+$ dynamic $>$ stands for the event itself (e.g., breaking) and the node THING symbolizes the entity involved in that event (e.g., the 
window). The bottom part of Figure 5 represents the causative event (e.g., a big stone breaking the window). The first EVENT is composed of an agentive THING [ ] (e.g., a big stone) that ACTS upon the THING [Y] (e.g., the window), resulting in the second EVENT illustrated by the window (THING Y) breaking (<+dynamic >). Pinker indicates that the broad-range rule encompasses information that the predicate of the effect event can be either GO or ACT, but cannot be the non-dynamic BE or HAVE. Innate linking rules will spell out the syntactic structure of a given semantic structure.

Learners acquire the broad-range lexical rules in two steps. First, learners acquire lexicosemantic structures of causative verbs. Second, they notice that some verbs are used not only as causative verbs, but also as intransitive verbs. However, the broad-range rules will lead them to overgeneralize the causative use of verbs. The non-existence of the overgeneralization errors, which constitutes the indirect negative evidence, prompts learners to form narrow-range rules, which will refrain them from applying the broad-range rules to causative verbs that cannot alternate. Pinker proposes the following narrow-range rules for the causative alternation, as shown in Figure 6.

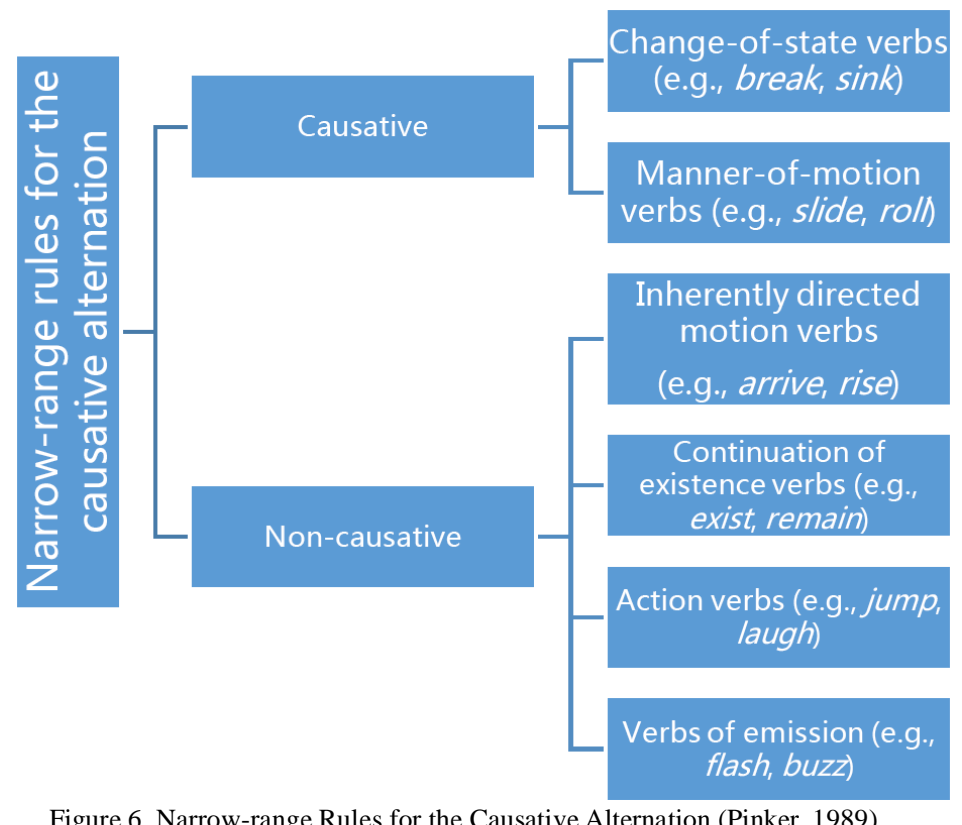

According to Pinker (1989), the overgeneralization errors learners make are either one-shot creations of the broad-range rules or are induced by incorrect semantic representations of particular verbs, which lead them to be wrongly categorized into a causative verb class. The second type of errors will disappear as a natural consequence of the fine-tuning of the verbs' semantic representations.

\section{The Entrenchment Hypothesis}

The Entrenchment Hypothesis, which is proposed by Braine and Brooks (1995), suggests that if a verb (e.g., happen) is repeatedly presented in a certain structure (e.g., an accident happened), it will impress the learners that this verb cannot be used in other structures and thus prevent the learners from associating this verb with other structures (e.g., an accident was happened). In other words, the higher the frequency at which a structure is presented for a particular verb, the less likely it will be used in other structures. To summarize, the Entrenchment Hypothesis highlights the important role of type frequency in learners' choice of verb argument structure. That is, verb types that learners encounter more frequently are acquired faster than the less frequent ones.

\section{E. The Interface Hypothesis}

Interface in linguistic studies refers to the connections or spaces where mappings happen. According to Ramchand and Reiss (2007), there are two understandings of interface. One is the link between language and non-linguistic cognitive domains such as psychology and neuroscience. The other is the connection between various linguistic modules, which include syntax-phonology, syntax-semantics, syntax-pragmatics, syntax-discourse, and so on. The first one is broad, while the second is narrow. It is often the narrow understanding that is followed by linguists.

The Interface Hypothesis is proposed by Sorace and Filiaci (2006). It suggests that language structures, which constitute an interface between syntax and other linguistic domains, are less likely to be fully acquired than structures that do not form an interface issue. For example, adult L2 learners are capable of fully acquiring target language properties that are purely internal components of the computational system of syntax, but are incapable of fully acquiring a syntactic-discourse language phenomenon. However, Tsimpli and Sorace (2006) find that interface issues do not pose the same difficulty to L2 learners. For example, the syntax-semantics interface, which involves formal properties of the language system alone, is easier to acquire than the syntax-discourse interface, which not only involves 
a processing of linguistic properties, but also a consideration of contextual appropriateness. Tsimpli and Sorace argue that the syntax-semantics interface represents a lower level of language acquisition while the syntax-discourse interface a higher level. Such a distinction is later called by Sorace and Serratrice (2009) the distinction between the internal interface, which includes syntax-phonology, syntax-morphology and syntax-semantics, and the external interface, which involves syntax-pragmatics and syntax-discourse. Sorace and Serratrice suggest that language structures at the external interface may be unattainable to adult L2 learners. Now the Interface Hypothesis, which has been reformulated to accommodate the recent research findings, states that adult L2 learners may succeed in acquiring purely syntactic properties that lie at the internal interfaces, but may not be fully successful in acquiring external interface issues. The variability in the end state grammar of adult L2 learners is termed as optionality. Sorace and Filiaci (2006) suggest that the optionality at the interface may be due to adult L2 learners' insufficient processing strategies to utilize syntactic and pragmatic knowledge.

\section{Prospects FOR Future StUdies}

\section{A. Continuing to Test the Validity of the Existing Hypotheses}

L2 acquisition of unaccusative verbs has received a lot of research attention. Three hypotheses have been specifically proposed to account for it. That is, the Unaccusative Hierarchy Hypothesis, the Unaccusative Trap Hypothesis and the Semantic Verb Class Hypothesis are exclusively associated with L2 acquisition of unaccusative verbs. The other two hypotheses, namely the Entrenchment Hypothesis and the Interface Hypothesis, are not uniquely applicable to unaccusative verbs in that they have a larger focus and address L2 acquisition in general. All these five hypotheses should of course be subject to more empirical tests in the future in that no consensus has been reached yet. The Unaccusative Trap Hypothesis, in particular, should be examined more extensively in that it has aroused much more controversy than others. The controversy over it stems from its' tendency to limit L2 acquisition of unaccusative verbs to the semantic-syntax interface only. That is, it is not compatible with other contributing factors such as subject animacy and pragmatic concerns. It is questionable whether L2 acquisition of unaccusative verbs proceeds in a fashion as neat as the description of the Unaccusative Trap Hypothesis. Therefore, more studies should be carried out in the future to test the validity of the Unaccusative Trap Hypothesis.

\section{B. Situating More Studies in the Usage-based Model of Language Learning}

Of the five hypotheses associated with L2 acquisition of unaccusative verbs, four of them are rule-based. These four hypotheses are the Unaccusative Hierarchy Hypothesis, the Unaccusative Trap Hypothesis, the Semantic Verb Class Hypothesis and the Interface Hypothesis. The Entrenchment Hypothesis is only the usage-based approach. It is therefore apparent that there is an imbalance in the theoretical perspectives adopted to view L2 acquisition of unaccusative verbs. In fact, the purely formalist view has proved to be inadequate. A case in point is the overpassivization error of unaccusatives, which is the most noticeable and most researched unaccusative-related phenomenon. The formalist account, as suggested by the Unaccusative Trap Hypothesis, views this error as L2 learners' overgeneralization of the be + Ven morphology of the English passive structure to overtly mark the movement of the sole argument of an unaccusative verb from the deep structure object position to the surface structure subject position. However, recent studies have revealed the effect of cognitive factors such as the presence of a conceptualizable agent in discourse on L2 learners' overpassivization errors ( Ju, 2000). That is, L2 learners are likely to passivize English unaccusative verbs when there is a conceptualizable agent in the given discourse. In addition to the conceptualizable agent interpreted from the given discourse, input frequency also plays a part in the overpassivization error. Lee et al (2008) find that L2 learners are less likely to passivize unaccusative verbs with higher frequencies than those with lower frequencies. And L2 learners are less likely to passivize non-alternating unaccusative verbs than alternating ones. This suggests that L2 learners' exposure to English unaccusative verbs can affect their knowledge of the appropriate use of these verbs, thus supporting the usage-based model of language learning. However, studies of this type are not as many as those approached from the generative perspective and therefore deserve more attention in the future studies.

\section{Contrasting L2 Learners of Different L1s}

There has been a heated debate on the potential influence of L1 on the L2 acquisition of English unaccusative verbs. Given the fact that L2 learners from various L1 backgrounds are all likely to make the overpassivization errors, many researchers argue that there is no L1 transfer effect in this interlanguage phenomenon (Balcom 1997; Ju 2000; Oshita 2000; Zobl 1989). Other researchers, however, find that the morphological properties of the L2 leaners' L1 affect their acquisition of the English causative alternation (Moore 1993; Kondo 2005; Chung 2016). Finding clear L1 morphological effects, Montrul (2000) argues that UG and L1 knowledge are not likely to affect all the linguistic domains in the same way at a given point of development. She concludes that L1 transfer is modular or selective in that it affects morphology but not argument structure. Gao (2009), however, finds that L1 t transfer does not proceed in a modular fashion despite the fact that the influence of L1 morphology is detected in certain conditions. He suggests that the modular view of L1 transfer is not empirically plausible and that a particular learner behavior results from both semantic and morpho-syntactic influence of L1. To solve this dispute, it is necessary to investigate and compare the acquisition of English unaccusative verbs by L2 learners of different L1s. 


\section{Making More Fine-grained Analysis of Verb Results}

Traditionally, English unaccusative verbs are studied on a group basis. That is, unaccusative verbs are divided into non-alternating and alternating groups, which are further divided into more subgroups according to the Unaccusative Hierarchy Hypothesis (Deguchi and Oshita 2004; Hirakawa 2000; Hwang 1999; Ju 2000; Oshita 1997; Yip 1995). However, Sikorska (2002) cautions that group results may be misleading because they conceal learner variations and word variations. She calls for the analysis of individual verbs, which can help to decide whether L2 learners will, as the UG theory would predict, treat verbs of the same class alike. Ju (2000) finds that there are significant differences in the susceptibility of English alternating unaccusative verbs to the overpassivization error by Chinese learners. But no such differences are found among the non-alternating unaccusative verbs. Jo (2018), however, finds that there are significant individual verb differences in Korean learners' tendency to passivize the English non-alternating unaccusatives verbs. Mo (2016) finds that there are significant between-verb variations in Chinese learners'acquisition of English causative alternation. His case studies show that Chinese learners mainly acquire the transitive use of break and the unaccusative use of sink. Therefore, there are wide variations in L2 learners' performance on English unaccusative verbs that belong to the same class. Such variations have not been thoroughly investigated. They deserve more attention in the future studies.

\section{E. Conducting More Online Processing Studies}

There has arisen a trend to study the online processing of English unaccusative verbs (Purdy 2010; Zhang and Qiao 2013; Zhao and Ge 2017; Zhu and Wang 2017). Various psychological methods have been used, which include self-paced reading studies, eye-tracking studies, cross-modal priming studies, ERP studies, and so on. These studies have the potential to unveil the mental representation and development associated with English unaccusative verbs. They represent an important direction for future studies.

\section{CONCLUSION}

Second language acquisition of English unaccusative verbs is a topic of heated discussion in the field of applied linguistics. So far five hypotheses have been proposed. These hypotheses are the Unaccusative Hierarchy Hypothesis, the Unaccusative Trap Hypothesis, the Semantic Verb Class Hypothesis, the Entrenchment Hypothesis and the Interface Hypothesis. This study takes a close look at these hypotheses and arrives at the following findings. First, the Unaccusative Hierarchy Hypothesis, the Semantic Verb Class Hypothesis and the Entrenchment Hypothesis apply to both L1 and L2, while the Unaccusative Trap Hypothesis and the Interface Hypothesis are aimed at L2 only. Second, the Unaccusative Hierarchy Hypothesis, the Unaccusative Trap Hypothesis and the Semantic Verb Class Hypothesis are uniquely concerned with unaccusative verbs, while the Entrenchment Hypothesis and the Interface Hypothesis address more types of verbs. Of course, all of them are not limited to English unaccusative verbs only. Third, the Unaccusative Hierarchy Hypothesis, the Unaccusative Trap Hypothesis, the Semantic Verb Class Hypothesis and the Interface Hypothesis are all rule-based by nature, while the Entrenchment Hypothesis is the only one that takes a usage-based view of language acquisition. Fourth, the Unaccusative Trap Hypothesis is the most controversial one, while the other four have received extensive empirical support. Fifth, these hypotheses, which have helped to provide a panoramic view of second language acquisition of unaccusative verbs, need to be further tested by future studies.

This study suggests that the future studies of second language acquisition of unaccusative verbs should pay more attention to the usage-based approach to language acquisition. It also calls for more attention to the possible between-verb variations, the possible role of L1 transfer and the online processing of unaccusative verbs.

\section{ACKNOWLEDGEMENTS}

This paper is a result of three research projects. The first one is Variations in EFL learners' acquisition of English unaccusative verbs: Implications for computer-aided language teaching practices (14YJC740068) funded by the Ministry of Education, China. The second one is A multi-factorial approach to L2 acquisition of English causative alternation (2017SJB1312) funded by the Department of Education, Jiangsu Province. The third one is Building up an excellent comprehensive English course (3510300818) funded by Wenzheng College, Soochow University.

\section{REFERENCES}

[1] Balcom, P. (1997). Why is this happened? Passive morphology and unaccusativity. Second Language Research 13, 1-9.

[2] Braine, M. \& P, Brooks. (1995). Verb argument structure and the problem of avoiding an overgeneralization grammar. In M, Tomasello. \& W, Merriman (eds.). Beyond Names for Things: Young Children's Acquisition of Verbs (pp. 353-376). Hillsdale, NJ: Erlbaum.

[3] Burzio, L. (1986). Italian syntax: A government-binding approach. Dordrecht: Reidel.

[4] Chomsky, N. (1981). Lectures on government and binding. Dordrecht: Foris.

[5] Chung, N. (2016). L1 Influence and Interface Effects in L2 English unaccusatives. English Teaching, 71, 75-04.

[6] Deguchi, A. \& Oshita, H. (2004). Meaning, proficiency and error types: Variations in nonnative acquisition of unaccusative verbs. In S. H. Foster-Cohen, M. S. Smith, A. Sorace and M. Ota, (Eds.), EuroSLA yearbook (pp. 41-65). Amsterdam: John Benjamins. 
[7] Gao, Y.S. (2009). Testing the modular view of L1 transfer in L2 acquisition of interface issues. Foreign Language Learning Theory and Practice, 29, 1-9.

[8] Hirakawa, M. (2000). Unaccusativity in second language Japanese and English. Unpublished PhD dissertation: McGill University.

[9] Hwang, J. B. (1999). Learnablity and the L2 development of English unaccusative verbs. Journal of the Applied Linguistic Association of Korea, 15, 65-87.

[10] Jo, R. (2018). Individual verb differences in Korean learners' use of English non-alternating unaccusatives. Foreign Language Education Research, 23, 43-64.

[11] Ju, M. K. (2000). Overpassivization errors by second language learners: The effect of conceptualizable agents in discourse. Studies in Second Language Acquisition, 22, 85-111.

[12] Kondo, T. (2005). Overpassivization in second language acquisition. International Review of Applied Linguistics in Language Teaching, 43, 129-161.

[13] Lee, S.K., Miyata, M. \& Ortega, L. (2008). A usage-based approach to overpassivization: The role of input and conceptualization biases. Paper presented at the $26^{\text {th }}$ Second Language Research Forum, Honolulu, HI. October 17-19.

[14] Levin, B. \& Rappaport Hovav, M. (1995). Unaccusativity: At the syntax-lexical semantics interface. Cambridge, MA: MIT Press.

[15] Mo, J.H. (2016). Between-verb variations in Chinese learners' acquisition of English alternating unaccusative verbs: A new test of the Semantic Structure Theory and the Entrenchment Hypothesis. Journal of Xi'an International Studies University, 24, $65-71$.

[16] Montrul, S. (2000). Transitivity alternations in L2 acquisition: Toward a modular view of L1 transfer. Studies in Second Language Acquisition, 22, 229-273.

[17] Moore, M. (1993). Second language acquisition of lexically constrained transitivity alternations: Acquisition of the causative alternation by second language learners of English. Unpublished $\mathrm{PhD}$ dissertation: University of South Carolina, Columbia.

[18] Oshita, H. (1997). “The unaccusative trap": L2 acquisition of English intransitive verbs. Unpublished PhD dissertation: University of Southern California.

[19] Oshita, H. (2000). What is happened may not be what appears to be happening: a corpus study of "passive" unaccusatives in L2 English. Second Language Research, 16, 293-324.

[20] Oshita, H. (2001). The unaccusative trap in second language acquisition. Studies in Second Language Acquisition, $23,279-304$.

[21] Perlmutter, D. (1978). Impersonal passives and the unaccusative hypothesis. In Proceedings of the 4th Berkeley Linguistics Society (pp. 157-189). Berkeley: University of California.

[22] Pinker, S. (1989). Learnability and cognition: The acquisition of argument structure. Cambridge, MA: MIT Press.

[23] Purdy, J. D. (2010). Unaccusativity and neurocognitive indices of second language acquisition: An ERP study. Unpublished Doctoral Dissertation: Columbia University.

[24] Ramchand, G. \& Reiss, C. (eds.) (2007). Oxford Handbook of Linguistic Interfaces. Oxford: Oxford University Press.

[25] Rothman, J., \& Slabakova, R. (2011). The mind-context divide: On acquisition at the linguistic interfaces. Lingua, 121, 568-576.

[26] Sikorska, M. P. (2002). Unaccusative and unergative verbs in the Spanish interlanguage of French and English speakers. Unpublished MA thesis: University of Ottawa.

[27] Sorace, A. (1995). Acquiring linking rules and argument structure in a second language. In L. Eubank, L. Selinker and M. S. Smith, (Eds.), The current state of interlanguage: Studies in honor of William E. Rutherford (pp. 153-175). Amsterdam: John Benjamins.

[28] Sorace, A. (2000). Review of Learnability and the lexicon: Theories and second language acquisition research. Linguistics, 36, 657-661.

[29] Sorace, A., \& Filiaci, F. (2006). Anaphora resolution in near-native speakers of Italian. Second Language Research, 22, 339-368.

[30] Tsimpli, I.M., Sorace, A. (2006). Differentiating interfaces: L2 performance in syntaxsemantics and syntaxdiscourse phenomena. In D. Bamman, T. Magnitskaia, and C. Zaller (eds.), Proceedings of the 30th annual Boston University Conference on Language Development, BUCLD 30 (pp. 653-664). Somerville, MA: Cascadilla Press.

[31] Yip, V. (1995). Interlanguage and learnability: From Chinese to English. Amsterdam: John Benjamins.

[32] Zhang, D.Q. \& X.M., Qiao. (2013). Online processing of the unaccusative constructions by Chinese English learners. Foreign Language World. 34, 12-21.

[33] Zhao, C. \& S.L., Ge. (2017). An online study on Chinese English learners' processing of English unaccusative verbs: A usage based approach. Modern Foreign Languages. 40, 80-90.

[34] Zhu, X.J. \& T.S., Wang. (2017). Online processing of English intransitive verbs by Chinese English learners. Foreign Language Education. 39, 55-59.

[35] Zobl, H. (1989). Canonical typological structure and ergativity in English L2 acquisition. In S. Gass and J. Schachter (Eds.), Linguistic perspectives on second language acquisition (pp. 203-221). Cambridge, UK: Cambridge University Press.

Junhua Mo was born in Changzhou, China, in 1977. He received his PhD in applied linguistics from Nanjing University in 2008. Since then, he has been teaching English in School of Foreign Languages, Soochow University. His major interests include second language acquisition, syntax and corpus linguistics. 